\title{
Hipernefroma en un niño de 6 años
}

\author{
DRES.: EDECIA OCHOA *, RODOLFO ARRIBAS $* *$, MANUEL NEIRA ***, DAVID MIRKIN ****.
}

El diagnóstico de hipernefroma, también llamado adenocarcinoma de células claras, se hace con muy poca frecuencia en la edad pediátrica. En un estudio realizado por Riches (1) en 195I, de 1746 casos de adenocarcinomas renales, solamente 5 correspondieron a pacientes que tenían entre 10 y 20 años, siendo el más joven de 11 años de edad.

Revisando la literatura nos encontramos con numerosos informes de 1 ó 2 casos, a raíz de los cuales los autores hacen una recopilación de publicaciones anteriores y revisan el tema $(2,3,4$, $5,6,7,8,9,10,11,12,13,14$,). Las experiencias más importantes corresponden a revisiones de periodos de más de una década. Hasta el momento, según nuestro conocimiento, los casos no alcanzan a 70 en la literatura mundial, siendo el menor de los pacientes un niño de 3 meses (13).

En este trabajo se presenta un caso de hipernefroma en un niño de 6 años, recientemente diagnosticado en el Hospital Roberto del Río, Unidad de Nefrología. Este es el primer paciente con esta patología en los últimos 10 años, en este Hospital. Tampoco hay publicaciones nacionales en este período.

Caso clínico. M.G.M., niño de 6 años; en Enero 1972 presenta heruaturia macroscópica de 15 días de duración, sin otra manifestación clínica. 9 meses después tiene otro episodio similar; no se constata edema, hipertensión, ni síntomas de infección urinaria baja: no hay compromiso del estado generat. Al examen físico se palpa riñón izquierdo algo doloroso. El hemograma y la velocidad de eritrosedimentación son normales, al

\footnotetext{
* Unidad de Nefrologia. Hospital R. del Río: Depto. de Medicina Experimental. Arca Norte. U. de Chile.

** Médico Residente. Depto. de Pediatrá, Hospital R. del Rio. trat Servicio de Radiologa. Hospital R. del Rio.

**ñ* Servicio de Anatomia Patológica. Hospital Roberto del Rio.
}

igual que la uremia. Los urocultivos seriados son negativos así como el PPD (2U). La pielografia de eliminación realizada el $30-X-72$ no reveló lesiones excepto una pequeña espina bífida en vértebra lumbosacra de transición.

Fue dado de alta siguiendo en control en consultorio externo de Nefrología, donde se pudo comprobar en 2 oportunidades hematuria. Entre cstos episodios el sedimento urinario fue negativo.

En Junio 1973 fue rehospitalizado a raíz de un nuevo episodio de hematuria macroscópica, que se acompaña esta vez de sensación opresiva en flanco izquierdo y de escalofríos. Al examen físico se comprobó excelente estado general, afebril. La presión arterial cra de $100 / 60 \mathrm{~mm}$. $\mathrm{Hg}$. No había edemas. El abdomen era blando, depresible, palpándose polo inferior de riñón izquierdo sensible. El hemograma era nocmal, la velocidad de eritrosedimentación-17 mm, a la hora, los urocultivos seriados fueron negativos. PPD (-). La búsqueda de bacilos de Koch en orina fue negativa en 5 oportunidades. La depuración de creatinina endógena fue normal $\left(155 \mathrm{ml} / \mathrm{min} / 1,73 \mathrm{~m}^{2}\right)$. La cistoscopia no mostró lesiones.

Con fecha 5 de Julio, 8 meses después de la primera, se realizó una nueva pielografía descendente.

Esta informa: defecto de llenamiento semilunar en $2 / 3$ externos de la pelvis renal izquierda, de contornos irregulares y bien precisos, con dislocación parcial de los cálices medio e inferior (Fig. 1). El resto del sistema de eliminación es normal, la vejiga también.

Se plantea el diagnóstico de neoplasia renal.

Se rcaliza arteriografía renal izquierda selectiva (Fig. 2) pot cateterización de arteria femoral derecha hasta la aorta, bajo anestesia general, ubicándose el extremo distal del catéter radio opaco a la altura del cuerpo de la $2^{\mathrm{a}}$ lumbar. La inyec- 


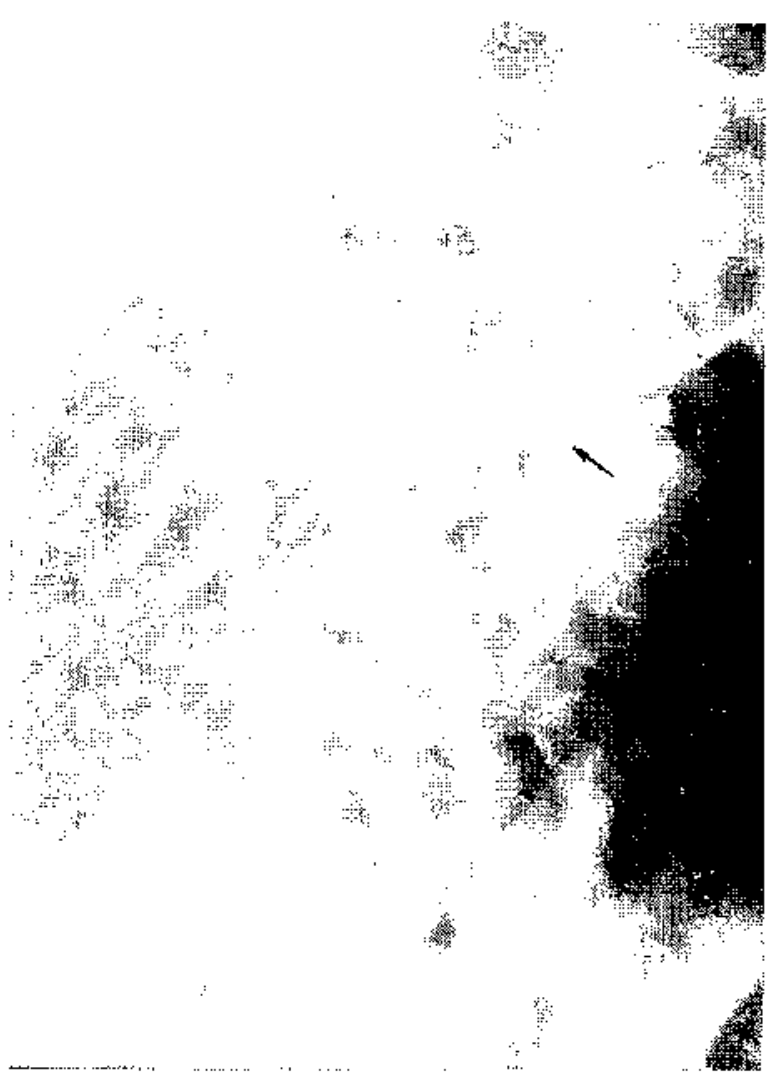

1.- Piclograbia descendente. La Mecha señala defecto de J Jina miento semilunar en la pclyis izquicra dewtminach nor th crecimiento tomoral.

ción del medio de contraste se hace bajo control de pantalla de televisión, practicándose una scric rá diográfica al terminar la inyección, a los 5,10 y 30 segundos. La sustancia opaca contrasta 3 arterias renales primitivas izquierdas que nacen directamente de la aorta irrigando las dos superiores la mitad superior del riñón y la inferior ef resto del parénquima renal. A nivel del polo inferior, ocupándolo totalmente, se observa una extensa zona de hiperemia que se exticnde hacia la parte media del riñón. Existe una bucna irrigación del polo superior del riñón, llamando da atención que la zona central del parénquima renal presenta hipoemia bien visible en todas las placas, especialmente en la fase tardía ncfrográfica. La conclusión radiológica es de lesiones compatibles con neoplersia renal maligna.

La radiografía de tórax es normal.

Se decidió la exploración quirúrgica, realizándose nefrectomia total izquierda y extirpación de pequeños ganglios hiliares.

ANATOMÍA PaTOLÓGICA. El riñón extirpado midió $9,5 \mathrm{~cm}$. $x 5,0 \mathrm{~cm}, x 2,5 \mathrm{~cm}$. y pesó $90 \mathrm{~g}$. (normal para la edad $70 \mathrm{~g}$.).

El polo inferior estaba remplazado por una masa tumoral lobulada de aproximadamente 2 cn. de diámetro, recubierta por la cápsula renal.

En la superficie de corte esta masa era de color rosado, de textura granular, friable y sin límite neto.

Se continuaba con una formación polipoidea que ocupaba el cáliz correspondiente y parte de la pelvis renal.

El parénquima renal restante y el uréter no presentaron alteraciones.

Sc realizaron improntas de la masa tumoral que coloceadas con Azul de toluidina revelaron grupos de células de citoplasmas abundantes $y$ claros, de núcleos pequeños y en muchos casos cxcéntricos. Se destacaban abundantes cuerpos laminares densos (calcosferitos). (Fig. 5).

En los cortes microscópicos el tumor está constituido por un fino estrona que separa formaciones papilares y ocasionalmente tubulares de epitelio neoplásico monomorfo y de bajo índice mitótico. (Fig. 3 y 4).

El tejido renal adyacente exhibe alteraciones inflamatorias de tipo crónico en relación con la compresión tumoral.

Cortes seriados del hilio renal descartan invasión tumoral vascular.

Junto con el rinión se extirparon 4 ganglios linfáticos del hilio renal.

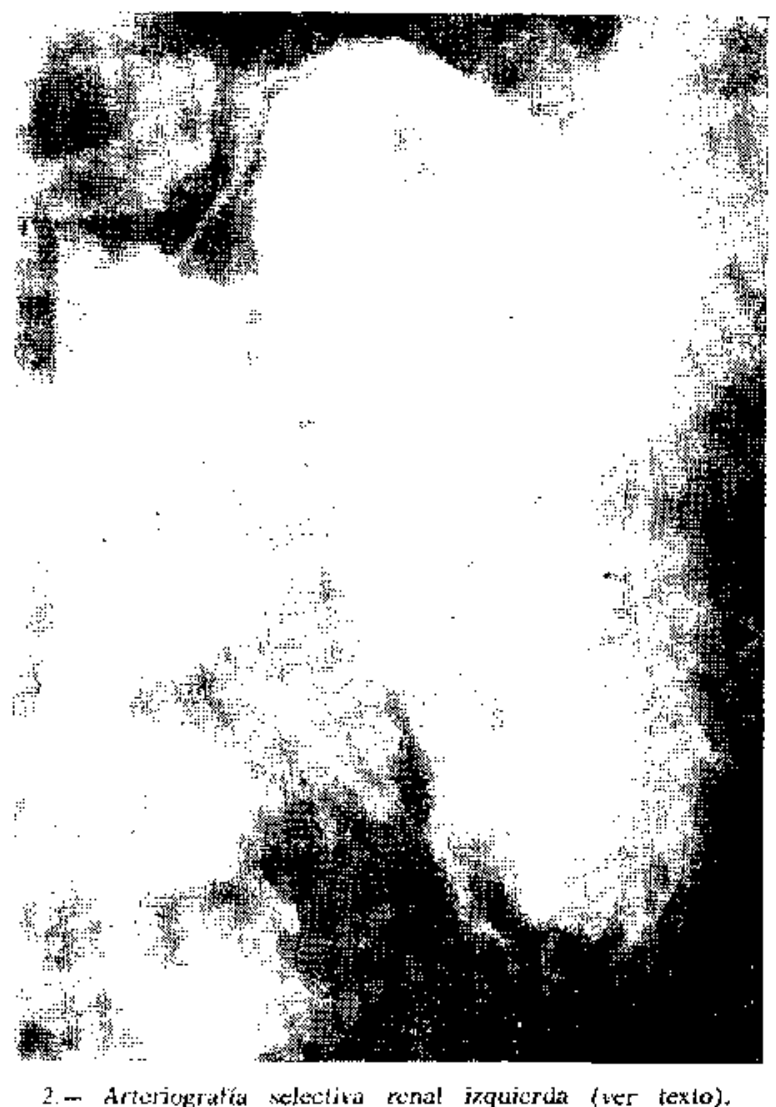



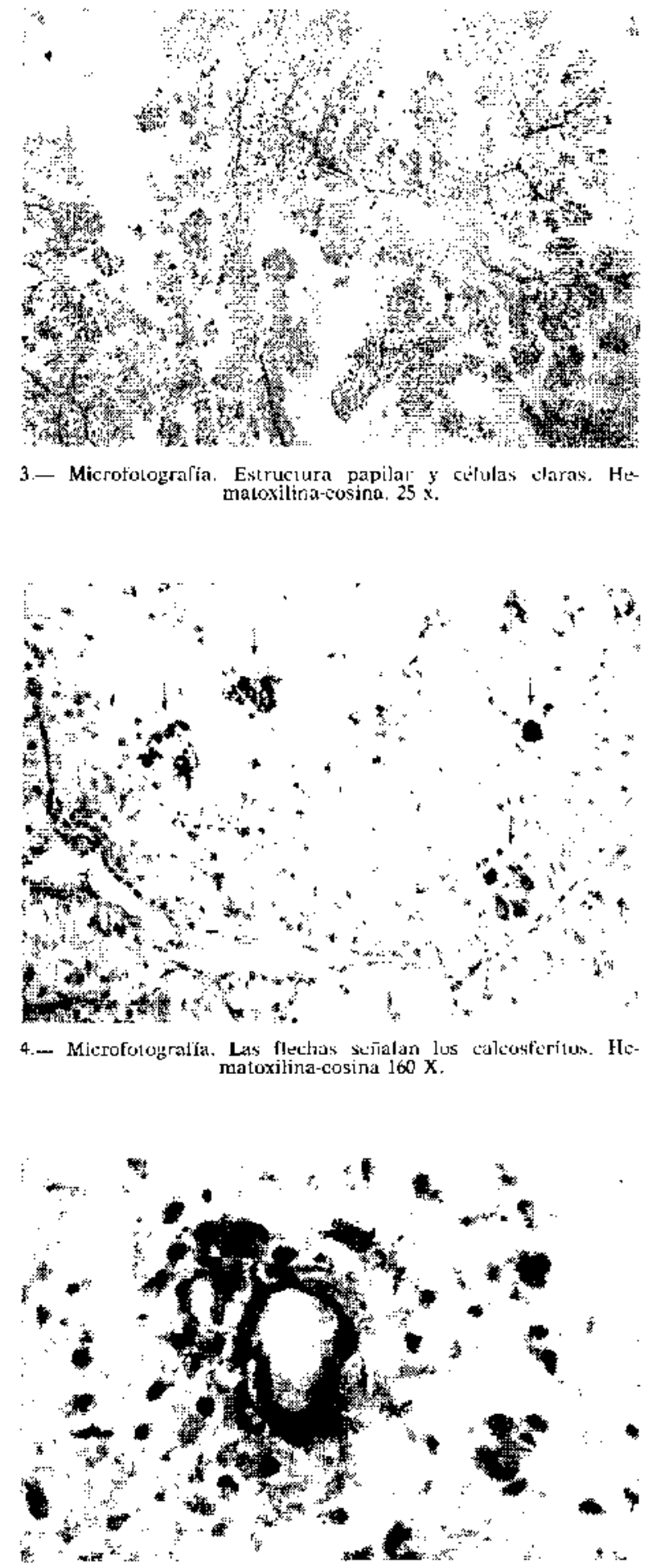

5.- Microfotografía, Еп el centro calcosferito redeido de ḉ.ulas çaras. Impronta del tumor. Anul de Toluidina. $400 \mathrm{X}$

Los 2 más grandes en una masa de menos de $3 \mathrm{~cm}$. de diámetro estaban casi totalmente esclerosados y contenían algunos islotes de proliferación tumoral.

Adyacente a éstos Ia masa de tejido linfático contenía una cavidiad quística sin clementos sspecíficos probablemente secundaria a necrosis.

Diagnóstico: Hipernefroma (Adenocarcinoma renal de células claras) con invasión de ganglios linfáticos.

No hubo complicaciones en el postoperatorio. El niño fue dado de altá en buenas condiciones, controlándose en cousultorio externo. No ha vuelto at presentar hematuria.

Hasta el momento lleva una evolución postoperatoria de 8 meses, sin ninguna molestia.

Comentario. Es con frecuencia difícil establecer el diagnóstico en la gran mayoría de las hematurias monosintomáticas. En el paciente que se presenta, la insistencia en el estudio permitió llegar a descubrir un tumor maligno, que constituye una rareza en pediatría.

Analizados los hechos retrospectivamente podemos ver que en este niño de $\mathbf{6}$ años, existían los síntomas clásicos: hematuria, dolor y masa palpable, antes de que el estudio radiológico permitiera comprohar la lesión. Eso sí, el dolor y la existencia de masa palpable no fueron relevantes.

Según diversos autores (2, 4-5) la tríada clá. sica del adulto con carcinoma renal es muy poco frecuente de ver en los niños. El síntoma más frecuente para algunos $(6,7,14)$ es la hematuria; otros autores ven con mayor frecuencia las masas abdominales, asociadas o no a síntomas digestivos altos vagos $(2,3,4,5)$.

El compromiso del estado general fue muy poco notorio a no existió en la mayoría de los casos publicados, al igual que en este paciente.

Tampoco son relevantes las alteraciones en el hemograma aun cuando se describe la existencia de policitemia (12) y ancmia (6).

El examen radiológico es diagnóstico casi en el $100 \%$ de los casos, mostrando como lesión más frecucnte distorsión de la pelvis y cálices, y calcificaciones en zona renal. Según algunos autores éstas son más frecuentes en el niño (15 a $25 \%$ ) que en el hipernefroma del adulto (5-10\%) (3, $4,6,7)$.

En nuestro paciente se realizó arteriografía renal selectiva que además de corroborar el diagnóstico, informó de las modificaciones de la irrigación sanguínea que produjo el tumor. Este proceujimiento se ha demostrado como de gran valor, permitiendo poner en evidencia la existencia de verdaderas fístulas artericvenosas (10). De acuerdo a cstudios realizados por Ofstad y Kolsaker (15) los cambios de vascularización provocados por el tumor producen alteraciones en la función del riñón afectado. Estas consisten en disminución de la excreción de $\mathrm{Ya}$ y $\mathrm{Cl}$ y del clearance osmolar por unidad de filtrado glomerular. Paralelamente, la excreción urinaria de inulina y paraaminohipurato son significativamente mayores en el lado afectado que en el sano. 
Estos hallazgos indican que bay hipoperfusión en el parénquima que rodea al tumor, probablemente por desviación de la circulación desde el tejido rental sino hacia el carcinona.

Debido a lo exiguo de las casuísticas recopiladas hasta el momento no existe una idea clara de los resultados del tratamiento y del pronóstico. Sin embargo, parece existir consenso en admitir que lo más indicado es el tratamiento quirárgico, y que hay relación estrecha entre el pronóstico y el grado de extensión del tumor en el momento de la extirpación y su tipo histológico $(3,5,6,11$, 16).

Según Dehner (6), que tiene seguimientos de 4 a 15 años, la sobrevida a los 5 años es de $57 \%$ y a los 3 años es de $64 \%$. De 15 casos, 5 murieron por el tumor $(33 \%)$ y 1 por otra causá.

De acuerdo a esta comunicación hay correlación de sobrevida con: a) formación de una pseudocápsula alrededor de! tumor, no importa de que tamaño sea, y ausencia de invasión vascular, b) Antigiiedad de los síntomas, c) Tipo histológico: los tumores de células claras con patrón mix to de trabéculas y túbulos, tendrán mejor pronóstico que los tumores papilares de células granulares. Los tumores de células claras, como cl presente constituyen la mayoría en los niños $(73 \%)$ (6).

La frecuencia de calcosferitos puede corresponder a un mecanismo de calcificación distrófica inespecífica a relacionarse con un efecto metabólico del propio tumor.

En este sentido podría relacionarse al sindrome hipercalcémico asociado con frecuencia a simpatomas, tumores del riñón, mama, ovario y otros en que se ha demostrado la formación de hormona polipéptida de cadena aminoácida larga ectópica (17).

Es discutible el uso de radioterapia. Su uso postoperatorio no modifica la sobrevida $(7,8)$. Hay que citar, eso sí, un caso publicado que fue catalogado de inoperable por su extensión y que luego de ser sometido a radiación combinada con actinomicina, clorambucil y Metotrexate, se redujo apreciablemente permitiendo su extitpación quirúrgica (11)

Por último es preciso recordar en relación al pronóstico, que hay algunos casos publicados en que aparecieron metástasis hasta 7 años después de la extirpación del tumor, lo cual obliga a seguimiento prolongado (9).

\section{RESUMEN}

Se presenta un caso de hipernefroma en un niño de 6 años.

Se destaca la hematuria clínica y el estudio angiográfico como elementos importantes para el diagnóstico. Se comentan los aspectos más relevantes del hipernefroma en la edad pediatrica.

\section{SUMMaRY}

A case of hypernephroma in a child 6 years old is presented.

Both clinical hematuria and angiographic $\mathrm{x}$ rays diagnosis are stressed.

Outstanding features of hypernephroma in pediatric age are commented.

\section{BibLIOGRAFÍA}

1.- Riches E. W., Griffiths I. H., Thackray A. C. New growths of the kidney and ureter. $\mathbf{~} \boldsymbol{r}_{1} \mathbf{J}$. Utol. 23: 297. 1951 .

2.-Siriggs C. D, Ainsworth $T$. Renal cell carcinoma in children: a review of the literature and report of two cases. J. Urol. 86; 728, 1961.

3.-Aron B. S. Gross M. Renal adenocarcinoma in infancy and childhood, evaluation of therapy and prognosis. J, Urol. 102: 497, 1969.

4.- Slowe $f$. A. Simpson C. B. Renal cell carcinoma in children. Report of two cases. Texas Reports on Biology and Medicine 26:629, 1968.

5.-Manson A. D. Sowle E. H. Mills S. D.. Deweerd J. $H$. Hypernephrom: in Childhood. J. Urol, 103: 336,1970 .

6.-Dehner L. P. Let'sma J. E., Price E. B. Renal cell carcinoma in Children. A. clínico pathologic study of 15 cases and review of the literature. J. Pediat. 76 : $358,1970$.

7.-Imbert $M$. C. Gerard-Marchant R. Schweisgush $O$., Nizelof $S$. Le catcinome tubulopapillaire du rein de l'enfant. A propos de 9 observations, Arn. Ped. Paris 15: 1094, 1968.

8.-Paima L. D., Kenny G. M. Murphy G. P. Childhood Renal Carcinoma. Cáncer 26: 1321, 1970.

9.-Yates-Bell A. J. Curdell B. S. Adenocarcinoma of the kidney in children. Br. J. Urol. 43: 399, 1971.

10.-Shanhern A. M. Srougi M., Leberman P. R. Hypernephroma in the pediatric age group. J. Urol. 104: 189,1970 .

11.- Fagast W. T. Clark $C$. W. Successful Treatment of inoperable hypernephroma in chilohood. J. Urol. 103: $652,1970$.

12.- Pochedly C, Sinatsirikui S., Penzer P. Renal cell carcinoma with extrarenal manifestations in a 10 months old child. Am. J. Dis. Child. 121: 528, 1971.

13.- Kubayashi A., Hoshino H., Ohbe Y., Sawaguchi Sh., Shimizu $K$. Bilateral Renal Cell Carcinoma. Arch. Dis. Child. 45: 141, 1970.

14.- Hara S., Bralley D. V., Brown H. P., Crump E. $P$. Hypernephroma in a three-years-old negro bay. Amer, J. Dis. Child. 116: \$59, 1968.

15.-Ofstad J., Kolsaker L. Renal Function studies in renal carcinoma. Clin. Sci. 39: 367, 1970.

16.-Grabstald H. Renal cell tumors. Surg. Cliz. N, Amer, 49: 337, 1969.

17.-Stovin, P. G. I. Syndromes of ectopic hormon production associated with pulmonary neoplasms. Am. Rew. Res. Dis, 92: 484, 1965. 